\title{
Small for Gestational Age Associated With Short Stature During Adolescence
}

\author{
A. ROBERTO FRISANCHO,${ }^{1}$ STEPHEN FIELDS,${ }^{1}$ AND \\ SHELLEY L. SMITH ${ }^{2}$ \\ ${ }^{I}$ Center for Human Growth and Development and Department of \\ Anthropology, University of Michigan, Ann Arbor, Michigan; \\ 'Department of Sociology and Anthropology, University of Texas at \\ Arlington, Arlington, Texas
}

\begin{abstract}
This study examined the relationship between intrauterine growth retardation and adolescent stature in a sample of 1510 White subjects ( 754 males and 756 females) who were evaluated at birth and at the ages of 15,16 , and 17 years. The subjects were classified into two groups based on birthweight, small for gestational age (SGA) and appropriate for gestational age (AGA), corresponding respectively to values below the 10th, and between the 11th and 99th, percentiles of gestational age and sex. Results showed that boys and girls born prematurely (gestational age $<37$ weeks of gestation) attained the same stature as those born at full term ( $>37$ weeks of gestation). In contrast, those born SGA were significantly shorter than their counterparts born AGA. The average reduction in stature was $4.9 \mathrm{~cm}$ for males and $2.9 \mathrm{~cm}$ for females. When the analysis included adjustments for parental stature (and adolescent's age at menarche for females), the average reduction in stature equaled about $3.5 \mathrm{~cm}$ for males and $2.0 \mathrm{~cm}$ for females. It is thus concluded that the stature deficit reflects a reduction in growth rate rather than delay in maturation. 1994 Wiley-Liss, Inc.
\end{abstract}

Studies of infants born small for gestational age (SGA) indicate that, in spite of some early catch-up growth, they remain smaller than those born appropriate for gestational age (AGA) due to slow growth during childhood (Brandt, 1986; Fitzhardinge and Inwood, 1989; Hadders-Algra and Touwen, 1990; Low et al., 1982). However, fewer studies have examined the extent to which the slow growth continues throughout adolescence. In view of the fact that adolescence is associated with the second growth spurt, it is possible that size differences may be overcome at that time. A recent report ( $\mathrm{Paz}$ et al., 1993) does not support this hypothesis, finding shorter stature at age 17 years in boys and girls born SGA relative to their peers born AGA. Similarly, based on a smaller matched-control sample, Westwood et al. (1983) report that SGA subjects remain smaller than AGA controls at ages 13-19 years. To further explore the possibility of a continued effect on growth in the adolescent period associated with being born SGA, the data sets from the Child Health and Development Studies (CHDS), available through the National Technical Information Service (NTIS) of the U.S. Department of Commerce, have been analyzed.

\section{MATERIALS AND METHODS}

The study population is based upon a sample of 1510 White subjects (754 males and 756 females) who were evaluated at birth and at the ages of 15,16 , and 17 years. Measurements of gestational age of newborns in weeks (derived from information on the last menstrual period), birthweight (for liveborn infants only), maternal age, maternal stature, paternal stature, adolescent age and stature, and total family income $(1=<\$ 2500 ; 2=\$ 2500-4999 ; 3=\$ 5000-$ $5999 ; \quad 4=\$ 6000-6999 ; \quad 5=\$ 7000-7999$; $6=\$ 8000-8999 ; 7=9000-9999 ; 8=\$ 10,000-$ 12,$499 ; 9=\$ 12,500-14,999 ; 10=\$ 15,000$ and over) were available for the 1510 White

Received March 23, 1993; accepted November 9, 1993

Address reprint requests to A.R. Frisancho, Department of Anthropology, Center for Human Growth of Development, $300 \mathrm{~N}$. Ingalls, University of Michigan, Ann Arbor, MI 48109-0406. 
TABLE 1. Characteristics of White subjects studied at birth and during adolescence

\begin{tabular}{lcccc}
\hline & \multicolumn{2}{c}{ Males } & \multicolumn{2}{c}{ Females } \\
\cline { 2 - 3 } Variable & $n$ & Mean \pm SD & $n$ & Mean \pm SD \\
\hline Gestation (weeks) & 764 & $39.7 \pm 1.9$ & 756 & $39.8 \pm 2.0$ \\
Birthweight (g) & 770 & $3490.5 \pm 522.4$ & 761 & $3341.2 \pm 500.2$ \\
Age (yrs) & 770 & $16.5 \pm 0.68$ & 761 & $16.5 \pm 0.68$ \\
Stature (cm) & 754 & $175.5 \pm 7.7$ & 756 & $163.9 \pm 6.7$ \\
Maternal stature (cm) & 758 & $163.8 \pm 6.3$ & 747 & $163.5 \pm 6.5$ \\
Paternal stature (cm) & 563 & $179.3 \pm 6.8$ & 554 & $179.5 \pm 7.1$ \\
Total family income) & 690 & $4.8 \pm 2.2$ & 700 & $4.7 \pm 2.2$ \\
\hline
\end{tabular}

${ }^{1}$ Total income scale: $1-<\$ 2500 ; 2=\$ 2500-4999 ; 3=\$ 5000-5999 ; 4=\$ 6000-6999 ; 5=\$ 7000-7999 ; 6=\$ 8000-8999 ; 7=\$ 9000-9999$; $8=\$ 10,000-12,499 ; 9=\$ 12,500-14,999 ; 10=\$ 15,000$ and over.

TABLE 2. Comparison of stature (cm) and total family income of adolescents born small for gestational age (SGA) and peers who were appropriate for gestational age (AGA)

\begin{tabular}{|c|c|c|c|c|c|c|c|c|}
\hline \multirow{2}{*}{$\begin{array}{l}\text { Birth } \\
\text { category }\end{array}$} & \multicolumn{2}{|c|}{$\begin{array}{c}\text { Adolescent } \\
\text { stature }(\mathrm{cm})\end{array}$} & \multicolumn{2}{|c|}{$\begin{array}{c}\text { Maternal } \\
\text { stature }(\mathrm{cm})\end{array}$} & \multicolumn{2}{|c|}{$\begin{array}{c}\text { Paternal } \\
\text { stature }(\mathrm{cm})\end{array}$} & \multicolumn{2}{|c|}{ Total income ${ }^{1}$} \\
\hline & $n$ & Mean \pm SD & $n$ & Mean \pm SD & $n$ & Mean \pm SD & $n$ & Mean \pm SD \\
\hline \multicolumn{9}{|c|}{ Males } \\
\hline Premature & 47 & $174.0 \pm 6.5$ & 48 & $162.9 \pm 5.7$ & 32 & $177.5 \pm 8.3$ & 47 & $5.1 \pm 2.4$ \\
\hline Full term & 702 & $175.5 \pm 7.7$ & 704 & $163.8 \pm 6.3$ & 526 & $179.4 \pm 6.7$ & 637 & $4.8 \pm 2.3$ \\
\hline F-test & & n.s. & & n.s. & & n.s. & & n.s. \\
\hline SGA & 75 & $171.1 \pm 7.8$ & 75 & $162.1 \pm 5.4$ & 53 & $178.5 \pm 8.2$ & 65 & $5.3 \pm 2.4$ \\
\hline $\mathrm{AGA}$ & 657 & $176.0 \pm 7.5$ & 657 & $164.0 \pm 6.3$ & 491 & $179.5 \pm 6.6$ & 603 & $4.7 \pm 2.1$ \\
\hline$F$-test & \multicolumn{2}{|c|}{$P<0.01$} & \multicolumn{2}{|r|}{ n.s. } & \multicolumn{2}{|r|}{ n.s. } & \multicolumn{2}{|r|}{$\mathrm{p}<0.05$} \\
\hline \multicolumn{9}{|c|}{ Females } \\
\hline Premature & 39 & $164.3 \pm 6.5$ & 38 & $164.2 \pm 4.3$ & 27 & $179.0 \pm 6.5$ & 36 & $4.5 \pm 2.3$ \\
\hline Full term & 711 & $163.9 \pm 6.7$ & 704 & $163.4 \pm 6.7$ & 524 & $179.5 \pm 7.1$ & 660 & $4.7 \pm 2.2$ \\
\hline$F$-test & & n.s. & & n.s. & & n.s. & & n.s. \\
\hline SGA & 81 & $161.4 \pm 6.6$ & 78 & $162.0 \pm 6.7$ & 56 & $178.0 \pm 8.1$ & 78 & $5.2 \pm 2.3$ \\
\hline AGA & 647 & $164.3 \pm 6.6$ & 642 & $163.6 \pm 6.5$ & 481 & $179.7 \pm 6.9$ & 597 & $4.6 \pm 2.1$ \\
\hline$F$-test & \multicolumn{2}{|c|}{$P<0.001$} & \multicolumn{2}{|r|}{ n.s. } & \multicolumn{2}{|r|}{ n.s. } & \multicolumn{2}{|r|}{ n.s. } \\
\hline
\end{tabular}

${ }^{1}$ Total income scale: $1=<\$ 2500 ; 2=\$ 2500-4999 ; 3=\$ 5000-5999 ; 4=\$ 6000-6999 ; 5=\$ 7000-7999 ; 6=\$ 8000-8999 ; 7-\$ 9000-9999$; $8=\$ 10,000-12,499 ; 9=\$ 12,500-14,999 ; 10=\$ 15,000$ and over.

adolescents $15-17$ years who had been measured at birth. Statures of the adolescents and their parents were measured at the time of examination. Subjects were measured standing erect and without shoes. Measurements were recorded in completed inches and sixteenths of an inch; the measurements were converted to centimeters.

The subjects, based on birthweight and gestational age, were classified into two groups, small for gestational age (SGA) and appropriate for gestational age (AGA), corresponding respectively to birthweights below the 10th, and between the 11th and 99th percentiles of gestational age. The statures of the two groups of adolescents were compared by analysis of variance (ANOVA) and analysis of covariance (ANCOVA), with the statures of the adolescent's parents as the covariates. Infants born with a gestational age $<37$ weeks were considered premature; those with a gestational age of $>37$ weeks, full term.

\section{RESULTS}

The general characteristics of the sample are given in Table 1 . The statures of both males and females are similar to the mean values expected for U.S. White populations of the same age (Frisancho, 1990). As shown in Table 2, adolescents born prematurely have attained the same stature as those born at full term. In contrast, SGA adolescents are significantly shorter than their AGA counterparts $(P<0.01$ for males; $P<0.001$ for females). The average reduction in stature equals $4.9 \mathrm{~cm}$ for males and $2.9 \mathrm{~cm}$ for females. The mean statures by age are shown in Figure 1. Comparison to U.S. reference data indicates that about $25 \%$ of SGA boys and $20 \%$ of SGA girls are 


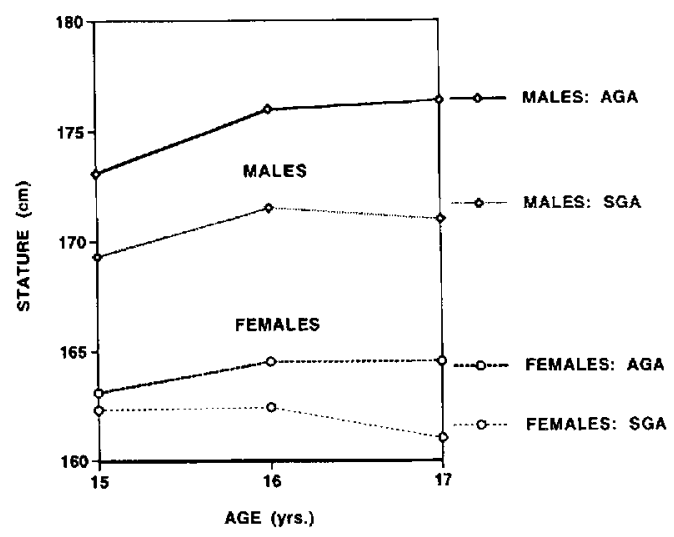

Fig. 1. Comparison of adolescent stature of males and females born small for gestational age with peers born appropriate for gestational age.

below the 10th age- and sex-specific percentiles during adolescence.

These differences are not attributable to income. The total income for SGA families is either higher than or equal to that of AGA families. Although there does appear to be a trend toward slightly greater stature for parents of AGA adolescents compared with parents of SGA adolescents, all comparisons are nonsignificant (Table 2 ).

Table 3 compares the mean statures of SGA and AGA adolescents adjusted for parental stature. (Statures of girls are adjusted for age at menarche as well.) It is evident that SGA individuals continue to be significantly shorter than AGA individuals during the adolescent period.

\section{DISCUSSION}

For this sample, infants born prematurely attain statures similar to those born full term. However very low birthweight premature infants may manifest a growth deficit, at least during childhood (Kitchen et al., 1992). Among those born SGA, the present findings suggest that there is no catch-up growth during adolescence. This finding is consistent with previous studies demonstrating that SGA is associated with short stature during childhood (Brandt, 1986; Fitzhardinge and Inwood, 1989; HaddersAlgra and Touwen, 1990; Low et al., 1982) and adolescence (Paz et al., 1993; Westwood et al., 1983). This study and the previous reports seem to suggest a biological stability that starts early in life and continues through adolescence.

An important question to address is the factors that account for the observed difference between adolescents born SGA and those born AGA. One possibility is that the difference is due to an interference with the process of developmental homeostasis. According to the concept of developmental homeostasis, stable development depends on the ability of the phenotype to compensate for genetic mutations and environmental disturbances (Lerner, 1954; Waddington, 1957). A productive way of testing the role of the interaction between the genotype and the phenotype is to evaluate the parent-offspring relationship in stature. As indicated in Table 2, parents of SGA adolescents do not differ significantly in stature from the parents of adolescents born AGA. However, a shown in Table 4 , the correlation between maternal stature and offspring stature for SGA adolescents $(r=0.15$ for boys and $r=0.35$ for girls) is significantly lower than that for AGA adolescents ( $r=0.51$ for boys and $r=0.54$ for girls). This indicates that maternal hereditary factors controlling the phenotypic expression of stature are less strong in SGA than in AGA adolescents. On the other hand, paternal hereditary factors controlling the phenotypic expression of stature are as strong in the SGA as in the AGA adolescents.

If this is the case, it can be inferred that negative intrauterine environmental factors reduce the buffering capacity of the genotype and affect the outcome of the developmental process. Previous studies indicate that maternal undernutrition, extremes in maternal age (either too young or too old), poor nutritional habits, and maternal smoking are associated with prenatal growth retardation (Frisancho, 1993). The net effect of these environmental factors is to decrease the genetic contribution toward the phenotypic expression of birthweight; the proportion of variation in birthweight attributable to the environment thus increases. For example, Little and Sing (1987) have shown that heritabilities for birthweight decrease among male infants of mothers who smoke. In the present analysis, $70 \%$ of SGA adolescents (males $=72 \%$; females $=69 \%$ ) were born to mothers who smoked during pregnancy. Thus, it is quite possible that the observed shorter stature of SGA adolescents reflects the influence of negative environ- 
TABLE 3. Comparison of stature (cm) of adolescent boys and girls born small for gestational age (SGA) and appropriate for gestational age (AGA), adjusted for parental stature (both sexes) and age at menarche (adolescent females)

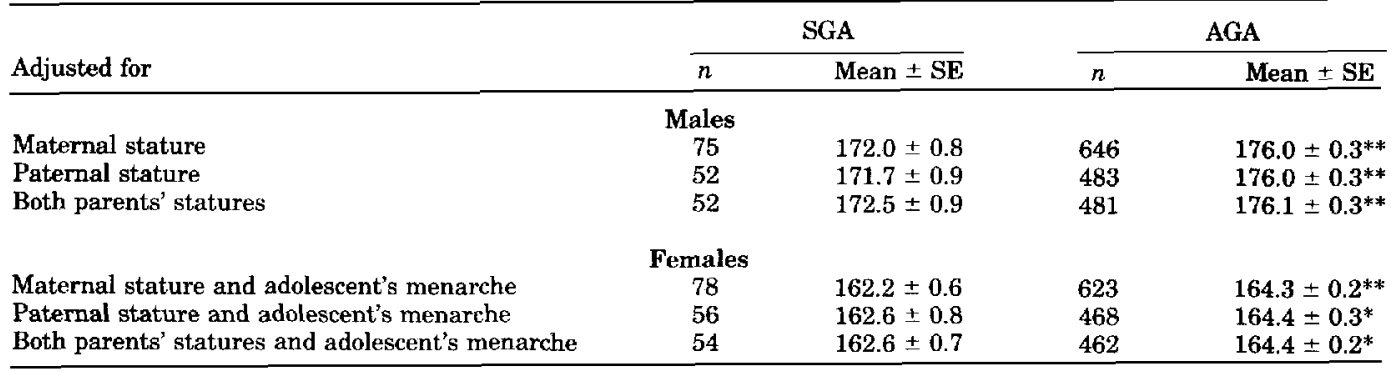

$* P<0.05$.

$* * P<0.01$.

TABLE 4. Comparison of parent-offspring correlations (r) for stature of adolescent boys and girls born small for gestational age (SGA) and appropriate for gestational age $(A G A)^{1}$

\begin{tabular}{|c|c|c|c|c|}
\hline & Mother & Mother & Father & Father \\
\hline Birth & Son & Daughter & Son & Daughter \\
\hline Category & $r$ & $r$ & $r$ & $r$ \\
\hline SGA & 0.15 & $0.35^{* *}$ & $0.54 \%$ & $0.46^{*}$ \\
\hline $\mathrm{AGA}$ & $0.51^{*}$ & $0.54^{*}$ & $0.46^{*}$ & $0.47^{*}$ \\
\hline
\end{tabular}

${ }^{1}$ The $n$ s are the same as those reported in Table 2.

${ }^{*} P<0.05$.

** $P<0.01$.

mental factors affecting the expression of genetic growth potential from the prenatal stage onward.

Another possibility is that the observed difference is related to a difference in the length of the maturation process, so that the SGA adolescents continue to grow for a longer period than their peers born AGA. To test this hypothesis, age at menarche was used. The results indicate that girls of both groups of adolescents have a similar mean age at menarche $(12.68 \pm 1.21$ years for SGA and $12.78 \pm 1.19$ years for AGA adolescents). Thus it appears that the stature deficit associated with the SGA adolescents reflects a reduction in the growth rate rather than a delay in maturation. This finding is consistent with that of Westwood et al. (1983), who reported no delay in bone age or sexual development in SGA relative to AGA adolescents.

In conclusion, the present study provides further evidence that infants born small for gestational age have an increased probability of short stature which continues through adolescence relative to infants born appropriate for gestational age.

\section{ACKNOWLEDGMENTS}

We thank Deborah Schechter for her assistance in manuscript preparation.

\section{LITERATURE CITED}

Brandt I (1986) Growth dynamics of low-birth-weight infants with emphasis on the perinatal period. In $F$ Falkner and JM Tanner (eds): Human Growth. A Comprehensive Treatise, Vol. 1. New York: Plenum Press, pp. 415-475.

Fitzhardinge PM, and Inwood S (1989) Long-term growth in small-for-date children. Acta Paediatr. Scand. 349:27-33.

Frisancho AR (1990) Anthropometric Standards for the Assessment of Growth and Nutritional Status. Ann Arbor: University of Michigan Press.

Frisancho AR (1993) Human Adaptation. Ann Arbor: University of Michigan Press.

Hadders-Algra M, and Touwen BCL (1990) Body measurements, neurological and behavioural development in six-year-old children born preterm and/or small-for-gestational-age. Early Hum. Dev. 22:1-13.

Kitchen WH, Doyle LW, Ford GW, and Callanan C (1992) Very low birth weight and growth to age 8 years. I: Weight and height. Am. J. Dis. Child. 146: $40-45$.

Lerner IM (1954) Genetic Homeostasis. New York: John Wiley.

Little RE, and Sing CF (1987) Genetic and environmen- 
tal influences on human birth weight. Am. J. Hum. Genet. 40:512-526.

Low JA, Galbriath RS, Muir D, Killen H, Pater B, and Karchmar J (1982) Intrauterine growth retardation: A study of long-term morbidity. Am. J. Obstet. Gynecol. 142:670-677.

Paz I, Seidman DS, Danon YL, Laor A, Stevenson DK, and Gale R (1993) Are children born small for gesta- tional age at increased risk of short stature? Am. J. Dis. Child. 147:337-339.

Waddington CH (1957) The Strategy of the Genes. London: Allen and Unwin.

Westwood M, Kramer MS, Munz D, Lovett JM, and Watters GV (1983) Growth and development of full-term nonasphyxiated small-for-gestational-age newborns: Follow-up through adolescence. Pediatrics 71:376-382. 